\title{
Surface deformation caused by shallow magmatic activity at Okmok volcano, Alaska, detected by GPS campaigns 2000-2002
}

\author{
Yousuke Miyagi ${ }^{1}$, Jeffrey T. Freymueller $^{2}$, Fumiaki Kimata ${ }^{3}$, Toshiya Sato ${ }^{4}$, and Dörte Mann ${ }^{5}$ \\ ${ }^{1}$ Institute of Seismology and Volcanology, Graduate School of Science, Hokkaido University, N10W8 Kita-ku, Sapporo 060-0810, Japan \\ ${ }^{2}$ Geophysical Institute, University of Alaska, Fairbanks, Fairbanks, Alaska 99775-7320, USA \\ ${ }^{3}$ Research Center for Seismology and Volcanology, Graduate School of Environmental Studies, Nagoya University, \\ Furou-cho, Chikusa-ku, Nagoya 464-8602, Japan \\ ${ }^{4}$ Research Center for Prediction of Earthquakes and Volcanic Eruptions, Graduate School of Science, \\ Tohoku University, Aoba-ku, Sendai 980-8578, Japan \\ ${ }^{5}$ Department of Geophysics, Stanford University, Stanford, CA 94305-2215, USA
}

(Received April 28, 2004; Revised August 31, 2004; Accepted September 2, 2004)

\begin{abstract}
Annual GPS campaigns were carried out at Okmok volcano in the Aleutian Islands, Alaska, between 2000 and 2002. Surface deformation detected by these measurements reveals that Okmok volcano has been inflating over these 3 years at a variable inflation rate. The horizontal displacements show a radial outward pattern, and there has been significant uplift of the caldera center. The uplift of the caldera center relative to the caldera rim was $\sim 2.1 \mathrm{~cm}$ during 2000-2001, and $\sim 6.7 \mathrm{~cm}$ during 2001-2002. The latter rate is quite consistent with that deduced from InSAR measurements spanning 1997-2000, but the deformation rate during 2000-2001 was much slower than during the preceding and succeeding periods. Shallow pressure source was inferred at a depth of $\sim 3.1 \mathrm{~km}$ beneath the approximate center of the caldera. The location of the source, $\sim 5 \mathrm{~km}$ laterally from the active vent, is consistent with that inferred from InSAR data during 1997-1998. The total increase in volume during 2000-2002 of the inferred source is $\sim 0.44 \times 10^{7} \mathrm{~m}^{3}$, which is $3-8 \%$ of the amount of volume erupted in 1997 . The GPS and InSAR data show that magma accumulation beneath Okmok was steady in rate and location during 1997-2002, except for a pause at some time between 2000 and 2001.
\end{abstract}

Key words: Okmok, GPS campaign, significant inflation, shallow magmatic activity.

\section{Introduction}

Okmok volcano is located on Umnak Island in the eastern Aleutian arc, where the Pacific Plate subducts beneath the North American Plate (Fig. 1) with a relative velocity of about $7 \mathrm{~cm} /$ year. Okmok is a large shield type volcano with a $10 \mathrm{~km}$-wide caldera and several post-caldera cones within the caldera. Okmok volcano has only one historically active vent, named Cone A, located in the southwest part of the caldera floor. It has erupted more than 10 times since the 1890s, including 4 major eruptions (Miller et al., 1998). The latest eruption occurred in February 1997 and produced a $\sim 5 \mathrm{~km}$ long lava flow extending from Cone A (Miller et al., 1998; Dean et al., 1998).

Prior to our study, SAR Interferometry (InSAR) measurements detected significant surface deformation at Okmok associated with the 1997 eruption, including pre-eruptive uplift, co-eruptive subsidence and post-eruptive uplift of the caldera center (Lu et al., 2000; Mann et al., 2002). However, the area of coherent data in the interferograms is limited to the northeastern part of the caldera. Usable SAR data after 2000 are limited, although Lu and Masterlark (2003) recently presented a number of new interferograms. Finally, due to steep topography, phase unwrapping has never been possible

Copy right(c) The Society of Geomagnetism and Earth, Planetary and Space Sciences (SGEPSS); The Seismological Society of Japan; The Volcanological Society of Japan; The Geodetic Society of Japan; The Japanese Society for Planetary Sciences; TERRAPUB. between the inside and outside of the caldera, which prevents the InSAR data from being referenced to the non-deforming far-field.

Repeated Global Positioning System (GPS) measurements provide a practical means to measure 3D crustal movements. Our GPS network (Fig. 1) includes sites both inside and outside the caldera, including locations where no interferograms are coherent. In this paper, we present the results from our GPS campaigns, which demonstrate that the deformation source at Okmok has changed with time.

\section{GPS Observation and Data Analysis}

We carried out GPS campaigns on Umnak Island, within and around Okmok caldera, in the summers of 2000, 2001 and 2002, and measured a total of 34 stations including a station DCH1 located in Dutch Harbor, $\sim 120 \mathrm{~km}$ east of Okmok (Fig. 1). Dual frequency receivers (Trimble 4000SSE, 4000SSI, and 5700 receivers) were used in these campaigns. We used the station FTGL as a local reference station for this network. The data at the local reference station were recorded throughout each campaign, and the other stations were occupied for at least one day each year, with 30 -second sampling rate and 10 degrees elevation cut off angle.

We analyzed the GPS data using Bernese GPS software Version 4.2 with the IGS precise orbits to estimate coordinates of all sites. In each year, we determined the coordinates 
Table 1. Comparison of the pressure source at Okmok volcano discussed by our study and Mann et al. (2002). Volume change is derived from source strength assuming the inflation results from addition of incompressible magma (Delaney and McTigue, 1994).

\begin{tabular}{cccccc}
\hline Period & Latitude $\left({ }^{\circ} \mathrm{N}\right)$ & Longitude $\left({ }^{\circ} \mathrm{W}\right)$ & Depth $(\mathrm{km})$ & Strength $\left(\times 10^{6} \mathrm{~m}^{3}\right)$ & Volume change $\left(\times 10^{6} \mathrm{~m}^{3}\right)$ \\
\hline $1997-1998(\mathrm{InSAR})$ & 53.432 & 168.131 & $3.5-4.1$ & $1.0-1.9$ & $4.2-7.9$ \\
$2001-2002(\mathrm{GPS})$ & 53.426 & 168.133 & 3.1 & 0.9 & 3.8 \\
$2000-2001$ (GPS) & 53.422 & 168.146 & 1.9 & 0.1 & 0.6 \\
\hline
\end{tabular}

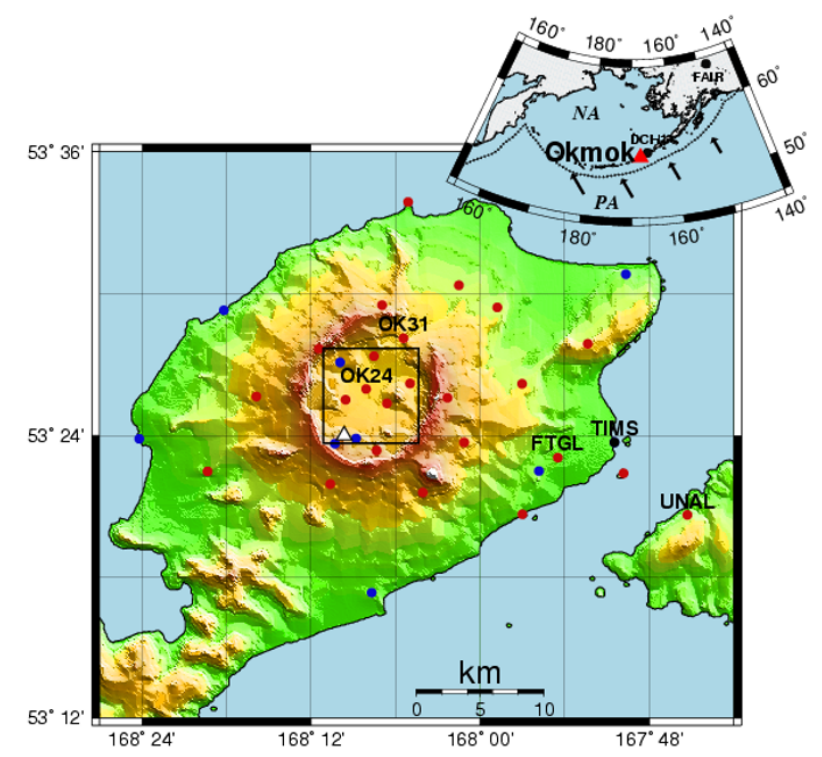

Fig. 1. Location map of the Aleutian Islands (inset) and GPS network on Umnak Island. A jagged line and arrows in the inset figure represent the plate boundary and relative velocity, respectively. Red circles represent the GPS stations established in 2000, and blue circles represent those established in 2001. The station TIMS (black circle) was established in 2002. An open triangle represents the active vent, called Cone A. A rectangle indicates the horizontal range for the grid search.

of the local reference station FTGL relative to the closest IGS station FAIR located in Fairbanks, Alaska, in the ITRF97 reference frame, and determined the coordinates of the other stations relative to FTGL. All data from each campaign were adjusted together to determine a single set of coordinates for each campaign. Uncertainties were also determined for each campaign, and the 2002 campaign had the smallest uncertainties and the 2001 campaign the worst.

All station displacements were estimated relative to FTGL for the periods 2000-2001 and 2001-2002, respectively. (Figs. 2 and 3). Both the horizontal and vertical components indicate inflation of Okmok caldera, but at different rate in each period. Because the uncertainties of each campaign's coordinates were different, the uncertainties of the displacements during 2000-2001 are higher than those during 20012002.

The sites FTGL and DCH1 (Dutch Harbor, $120 \mathrm{~km}$ east) moved less than $1 \mathrm{~cm}$ in each component during 2000-2002 relative to each other. This relative motion may include a component due to the deformation of Okmok, and a component due to along-strike variation in the strain from the locked subduction interface. Because of the possible impact of the tectonic component, we did not use DCH1 in the remaining analysis. In this paper we present and model dis- placements relative to FTGL to minimize the impact of tectonic motions.

\section{Results and Discussion}

Deformation during 2000-2001 was relatively slow, both horizontal and vertical displacements were less than $2 \mathrm{~cm}$ (Fig. 2). The displacements for the period 2001-2002 were much larger in magnitude than the displacements during 2000-2001 (Fig. 3). This difference is significantly larger than the uncertainty in the data. The 2001-2002 horizontal displacements show a clear radial outward pattern from the caldera center with $\sim 4 \mathrm{~cm}$ of maximum displacement (Fig. 3(a)). The vertical displacements show significant uplift, $8 \mathrm{~cm}$ at the station closest to the caldera center (Fig. 3(c)). The displacements at the sites inside the caldera are significantly larger in magnitude than those outside the caldera, which indicates that the source is located at shallow depth below the caldera center.

Figure 4 shows a history of uplift at the caldera center relative to the caldera rim, including results from InSAR measurements (Lu et al., 2000; Mann et al., 2002; Mann, 2002). This reveals that the inflation rate during 2001-2002 derived from GPS data corresponds to the rate during 1997-2000 derived from InSAR data, which may represent a typical uplift rate. The 2000-2001 uplift rate is much slower than both the preceding and succeeding period.

We model the inflation for both periods using a spherical pressure source (Mogi, 1958) expressed by following equations;

$$
\begin{aligned}
& \Delta h(r)=C d /\left(r^{2}+d^{2}\right)^{3 / 2} \\
& \Delta r(r)=C r /\left(r^{2}+d^{2}\right)^{3 / 2}
\end{aligned}
$$

where $\Delta h$ and $\Delta r$ are the vertical and radial displacements, $d$ is the source depth, $r$ is the radial distance from the source, and $r$ is the source strength, which is expressed by $C=$ $3 a^{3} \Delta P / 4 \mu$, with source radius $a$, pressure change $\Delta P$, and modulus of rigidity $\mu$. A grid search was used to estimate the best fitting parameters: horizontal position, depth and strength of the source. Grid ranges are $168.070-168.190^{\circ} \mathrm{W}$ in longitude and $53.390-53.460^{\circ} \mathrm{N}$ in latitude for horizontal position, $1.0-6.0 \mathrm{~km}$ for depth and $0-0.0020 \mathrm{~km}^{3}$ for strength, and increments are $0.001^{\circ}, 0.1 \mathrm{~km}$ and $0.0001 \mathrm{~km}^{3}$, respectively. We calculated the misfit of each trial model by comparing the model displacements relative to FTGL to the corresponding observations, weighted by the observation uncertainties. For 2001-2002, we find the best fitting inflation source lies $\sim 3.1 \mathrm{~km}$ below the approximate geometric center of the caldera (Table 1). The model explains well both the horizontal and vertical components, especially the large displacements inside the caldera (Figs. 3(a), 3(c)), and results 
(a)

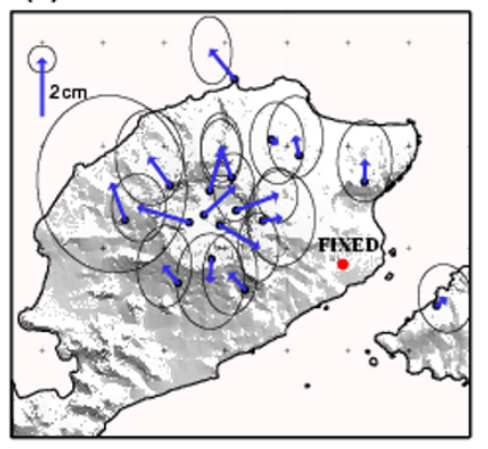

(b)

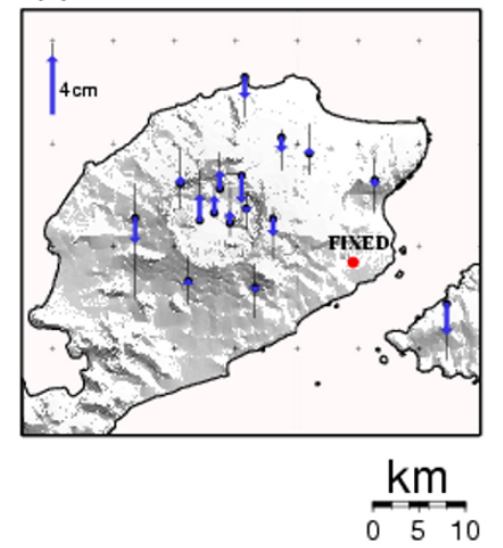

Fig. 2. (a) Horizontal and (b) vertical velocities observed by GPS measurements between 2000 and 2001. Error ellipses indicate $95 \%$ confidence regions. All vectors are determined relative to the station FTGL.

(a)

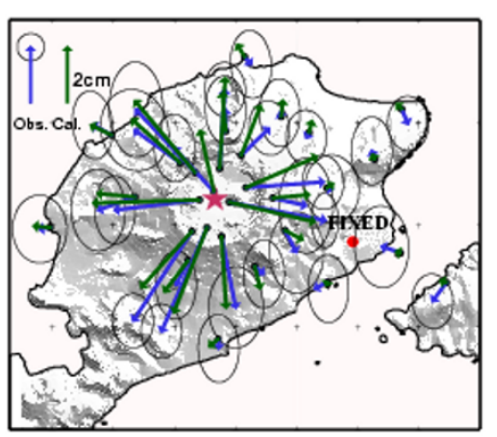

(c)

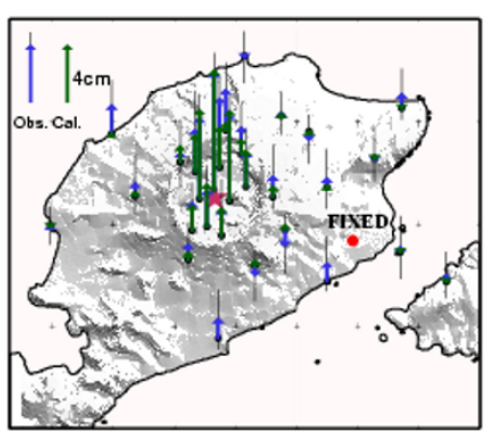

(b)

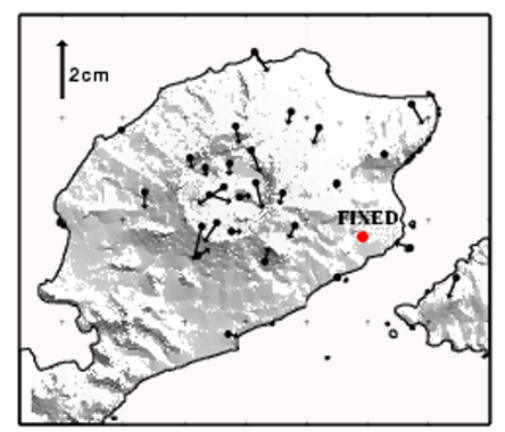

(d)

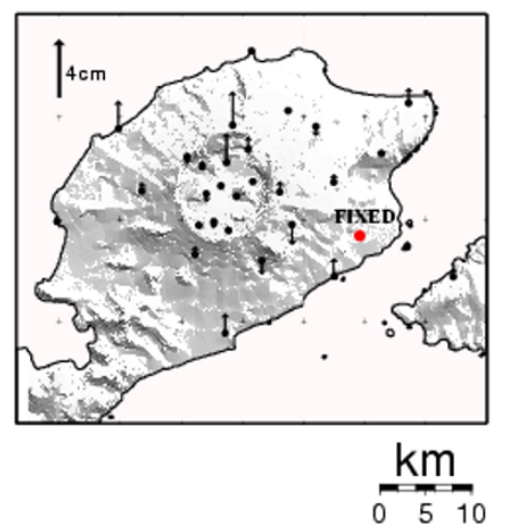

Fig. 3. (a) Horizontal and (c) vertical velocities observed by GPS measurements between 2001 and 2002, and calculated from a best fit Mogi source, which is located $3.1 \mathrm{~km}$ beneath the approximate caldera center. Error ellipses indicate $95 \%$ confidence regions. A star represents the horizontal position of the inferred source. (b), (d) Residuals between observed and calculated values for each component.

in small residuals for each component (Figs. 3(b), 3(d)). The best-fitting model parameters show slightly shallower depth and smaller strength than those estimated from the InSAR data during 1997-1998 (Table 1) (Mann et al., 2002). The inferred inflation source for 2000-2001 lies similar horizontal position as the inferred source for both 2001-2002 and 1997-1998 (Mann et al., 2002), but the 2000-2001 source depth and strength are quite shallow and small (Table 1). Assuming the inflation results from the addition of volume of incompressible fluid (Delaney and McTigue, 1994), the source strength can be related to a volume change in the sub- surface magma body (Table 1). In this case, a volume change in the subsurface magma body equals to $4 \pi C / 3$, assuming the Poisson's ratio is 0.25 . The total reduced $\chi^{2}$ misfits, which means $\chi^{2}$ divided by a number of observed sites, of the 2000-2001 displacements to the best-fit spherical pressure source are larger than those for the period 2001-2002 (Table 2).

We estimate $\sim 0.44 \times 10^{7} \mathrm{~m}^{3}$ of volume increase in the source during 2000-2002, assuming that the source strength results from volume change at constant pressure. The 1997eruptive volume was estimated as $5.2-9.2 \times 10^{7} \mathrm{~m}^{3}$, from a 
Table 2. The reduced $\chi^{2}$ misfits between the observed data and the calculated data from best-fit pressure sources.

\begin{tabular}{cccc}
\hline Period & N-S & E-W & U-D \\
\hline $2000-2001$ & 1.30 & 1.95 & 2.54 \\
$2001-2002$ & 1.40 & 1.29 & 1.51 \\
\hline
\end{tabular}

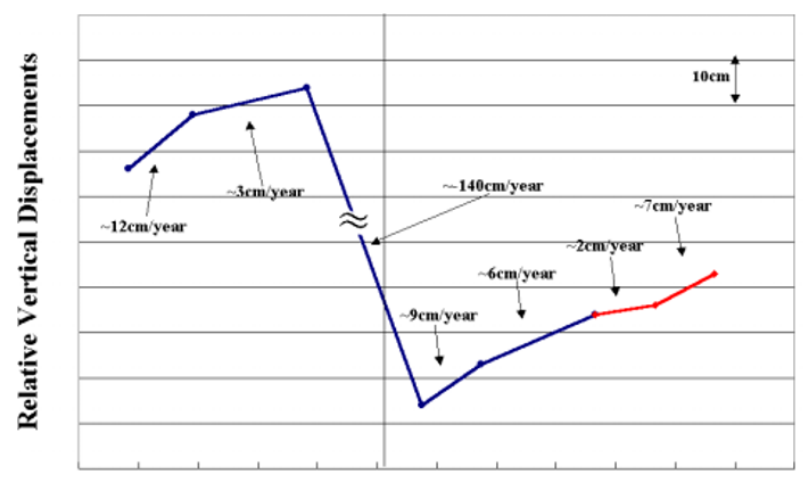

$199219931994 \quad 199519961997199819992000 \quad 20012002 \quad 2003 \quad 2004$

Fig. 4. Time series of vertical deformation at the caldera center relative to the caldera rim. Blue lines represent the uplift and subsidence rates detected by InSAR measurements (Lu et al., 2000; Mann et al., 2002). Red lines represent the uplift rates during 2000-2002, detected by GPS measurements at OK24 relative to OK31, see Fig. 1 for those locations. The thin vertical line represents the latest eruption in February 1997.

model fit to the syn-eruptive deformation observed by InSAR (Mann et al., 2002). Lu et al. (2003) also estimated the eruptive volume of $7-14 \times 10^{7} \mathrm{~m}^{3}$, using the bulk volume of the lava flow estimated by a TOPSAR digital elevation model (DEM) and pre-eruptive DEM based on USGS maps. The estimated volume change from 2000-2002 GPS data is 3-8\% of the erupted volume in the 1997 eruption.

Assuming a magma volume flux at the average 19972002 rate, it would take 20-35 years to restore the volume erupted in the 1997 eruption. This estimated recurrence time is consistent with the $\sim 25$ year average time interval between major eruptions.

During the 5 years following the 1997 eruption, magma has accumulated at nearly the same location and depth beneath the Okmok caldera, and at nearly the same rate except for a lower rate between 2000 and 2001. Except for the lower rate during that one period, variations in the source are too small to resolve with the existing data. This implies a generally steady, although not constant, supply of magma to shallow depth; the existence of a pause in an otherwise regular pattern of inflation could result from the arrival of magma in discrete pulses a few to several months apart.

The one of features of Okmok volcano is that the active vent shown in Fig. 1 is located at $\sim 5 \mathrm{~km}$ southwest of the inferred magma body. Although Mann et al. (2002) mentioned a possibility of a lateral magma transport from the source to the vent, there has been no obvious data from our GPS campaigns to support the possibility.

\section{Conclusion}

We have established a well-distributed GPS network at Okmok volcano on Umnak Island. Total displacements over two years are as large as $5 \mathrm{~cm}$ of radial displacement and $\sim 9 \mathrm{~cm}$ of uplift. Rapid inflation of Okmok volcano during 2000-2002 is caused by inflation of a shallow magma body beneath the geometric center of the caldera. However the inflation rates show episodic change with the inflation rate during 2001-2002 being larger in magnitude than the rate during 2000-2001. Considering the previous results from InSAR measurements, this suggests steady inflation after the 1997 eruption at the same location and depth, except for a reduction in magma flux between 2000 and 2001.

We modeled the observed data for both periods using a spherical pressure source $\sim 3.1 \mathrm{~km}$ below the caldera center. The source volume increase during 2000-2002 is estimated to be $\sim 0.44 \times 10^{7} \mathrm{~m}^{3}$. The source location is not distinguishable from a model fit to InSAR data from 1997-1998. We also estimated an eruption recurrence time of 20-35 years for 1997-sized eruptions from the volume change rate of the source, which is consistent with $\sim 25$ years average time interval between major eruptions.

Alaska Volcano Observatory installed three continuous GPS stations at Okmok volcano in summer 2002. Future work will evaluate changes of the inflation rate by the data from the continuous GPS network.

Acknowledgments. Part of this study is supported by the Japan Aerospace Exploration Agency (JAXA, previously named the National Space Development Agency of Japan or NASDA), through the program of Arctic Research projects using IARC (International Arctic Research Center)-NASDA Information System (INIS). Alaska Volcano Observatory (AVO) provided logistical support and salary support for J. Freymueller.

\section{References}

Dean, K., M. Servilla, A. Roach, B. Foster, and K. Engle, Satellite monitoring of remote volcanoes improves study efforts in Alaska, Eos. Trans. $A G U$, 79(35), 413, 422-423, 1998.

Delaney, P. T. and D. F. McTigue, Volume of magma accumulation or withdrawal estimated from surface uplift or subsidence, with application to the 1960 collapse of Kilauea volcano, Bull. Volcanol., 56, 417-424, 1994.

Lu, Z. and T. Masterlark, Magma supply dynamics of Okmok volcano inferred from interferometric SAR, Eos Trans. AGU, 84(46), Fall Meet. Suppl., F1631, 2003.

Lu, Z., D. Mann, J. T. Freymueller, and D. J. Meyer, Synthetic aperture radar interferometry of Okmok volcano, Alaska: Radar observation, $J$. Geophys. Res., 105, 10791-10806, 2000.

Lu, Z., E. Fielding, M. R. Patrick, and C. M. Trautwein, Estimating lava volume by precision combination of multiple baseline spaceborne and airborne interferometric synthetic aperture radar: The 1997 eruption of Okmok volcano, Alaska, IEEE Trans. Geoscience and Remote Sensing, 41, 1428-1436, 2003.

Mann, D., Deformation of Alaskan Volcanoes, Measured Using SAR Interferometry and GPS, Ph.D. Thesis, University of Alaska Fairbanks, 122 pp., 2002.

Mann, D., J. Freymueller, and Z. Lu, Deformation associated with the 1997 eruption of Okmok volcano, Alaska, J. Geophys. Res., 2001JB000163, 2002.

Miller, T. P., R. G. McGimsey, D. H. Richter, J. R. Riehle, C. J. Nye, M. E. Yount, and J. A. Dumoulin, Catalog of the historically active volcanoes of Alaska, U.S. Geol. Surv. Open File Rep., 98-582, 1998.

Mogi, K., Relations between the eruptions of various volcanoes and the deformations of the ground surface around them, Bull. Earthquake Res. Inst. Univ. Tokyo, 36, 99-134, 1958.

Y. Miyagi (e-mail: yousuke@eos.hokudai.ac.jp), J. T. Freymueller, F. Kimata, T. Sato, and D. Mann 